\title{
Fire evacuation in high-rise buildings: a review of human behaviour and modelling research
}

\author{
Enrico Ronchi ${ }^{*}$ and Daniel Nilsson
}

\begin{abstract}
A review of literature related to fire evacuation in high-rise buildings was carried out with the following objectives, (1) to identify the key behavioural factors affecting the performance of people during a fire in a high-rise building, the singularities associated to this type of buildings and areas of future research; (2) to review the procedures and strategies currently adopted in high-rise buildings; (3) to review and analyse the capabilities of evacuation models by reviewing their current characteristics and applications in the context of high-rise building evacuations. The review included both findings on human behaviour in high-rise buildings and modelling techniques and tools. Different categories of building use were taken into account, namely office buildings, residential buildings and health care facilities. The individual or combined use of different egress components was analysed. Egress components include the use of stairs, elevators as well as alternative means of escape (e.g., sky-bridges, helicopters, etc.). The effectiveness of the egress components is strongly affected by the building use and the population involved. The review shows that evacuation models can be effectively employed to study relocation strategies and safety issues associated with high-rise buildings. The suitability of egress models for high-rise building evacuations is associated with their flexibility in representing different egress components and complex behavioural processes. The review highlights that there is not a definitive model to be used but that the predictive capabilities of evacuation modelling techniques would be enhanced if more than one model is employed to study different egress aspects. Future research and model developments should focus on the study of the impact of staff actions, group dynamics and people with disabilities. Given the increasing height of buildings and the gradual reduction in the physical abilities of the population, the effects of fatigue on evacuation need further studies.
\end{abstract}

Keywords: High-rise building evacuation; Human behaviour in fire; Egress modelling; Stair evacuation; Evacuation elevators; Occupant relocation strategies

\section{Introduction}

According to the definition of the National Fire Protection Association (NFPA 2012), high-rise buildings are defined as "buildings greater than 75 feet (approximately $23 \mathrm{~m}$ ) in height where the building height is measured from the lowest level of fire department vehicle access to the floor of the highest occupiable story". According to Hall (2011), the main building uses that can be identified to categorise this type of buildings are office buildings, residential buildings (e.g., hotels, apartment buildings) and health care facilities. Each of these categories presents different characteristics from the point of view of both the infrastructure and the population. The analysis

\footnotetext{
* Correspondence: enrico.ronchi@brand.lth.se

Department of Fire Safety Engineering and Systems Safety, Lund University,
} Box 118, 22100 Lund, Sweden of the building use is therefore crucial to predict the possible behaviour of the occupants and provide an adequate fire safety design. In fact, evacuation dynamics may be substantially affected by the infrastructure and the evacuating population under consideration, e.g. physical abilities of the occupants, occupant familiarity with the environment, etc.

Although building codes establish the minimum requirements for the design of a high-rise building, additional life safety features are often necessary to mitigate the issues deriving from their complexity and the additional difficulties in fire-fighting and rescue operations. The perspective of the technical international guidance, e.g., NFPA101 in the U.S. (NFPA 2012), or the Approved Document B (The Building Regulation 2006) in the UK is to provide information on the design of the egress

\section{它}


components (e.g., geometric characteristics of the stairs) that can be applied for high-rise buildings. On the other hand, further information on the behavioural issues associated with the egress performance during high-rise building evacuations is still required. General concepts can be employed although additional specific recommendations may be required given the particular features of this type of building. Dedicated recommendations have been provided by national and international committees, e.g. the GB50045-95, Code for Fire Protection Design of Tall Buildings in China (GB50045-95 2005), the Fire Safety Requirements for super high-rise residential buildings in Singapore (Singapore Civil defence Force 2006) or chapter 7 of the Fire and Life Safety of National Building Code of India (Bureau of Indian Standards 2005).

Recent US statistics (Hall 2011) show that an average of 15,700 fires were reported in high-rise buildings per year in the USA, causing a total of 53 deaths, 546 injured, and $\$ 235$ million in direct property damage per year. High-rise buildings present a lower number of fatalities than lowrise buildings of the same type. However, the attention on this type of building is raised by the fact that even a single high-rise building fire may cause a significant number of fatalities due to the possible high number of people involved. Researchers have performed in-depth analyses of particularly memorable incidents in order to study the high-rise fire problem. Examples are available in the literature, such as the MGM Grand Hotel Fire where the total number of fatalities was 85 (Best and Demers 1982, Clark County Fire Department 1981), the bombing of the Oklahoma Murray Federal Building resulting in 168 fatalities (Mallonee et al. 1996) or the Chicago Cook County Administration Building Fire (Proulx and Reid 2006) that resulted in 6 fatalities.

The research on high-rise buildings became a growing concern to safety committees working on codes towards the end of the 1960s (Galbreath 1969; General Services Administration, 1971; Melinek and Booth 1975). The design of exit stairs was the main issue analysed at the time, providing formulas for exit stair width and for estimates of minimum total evacuation times. Significant work in this area was performed in the 1970s and 1980s (Pauls 1978; Pauls 1988). The focus of these studies was the application of the hydraulic movement models taking into consideration the behavioural factors. This permitted the inclusion of the pre-evacuation activities of the occupants in the analysis of the actual evacuation times of tall buildings.

More recently, the sense of awareness on this topic was raised by the World Trade Centre terrorist attack of 9/11 (Averill et al. 2005). The event resulted in a paradigm shift in the assessment of high-rise building safety. In fact, it showed the importance of providing robust means of egress and the need for a detailed investigation of the interactions between the infrastructure, the procedures and the behaviour of the occupants (Galea et al. 2008a; 2008b).

Several questions have been prompted by the WTC attack regarding the adequacy of our current safety regulations and emergency procedures for high-rise buildings. For what type of evacuation scenarios should we design a high-rise building? What egress components are recommended to evacuate a high-rise building? Are elevators suitable for evacuation purposes? What design measures or procedures should be employed to improve egress efficiency? These questions do not have a simple answer and the specifics of each building need to be taken into account. In addition, the lack of knowledge in terms of the behavioural aspects taking place during a high-rise building evacuation is still evident (Kuligowski 2011). Therefore, each individual variable needs to be investigated in order to provide specific recommendations on single aspects of the evacuation process. For this reason, there is a need to perform a review of the literature available on the main variables affecting high-rise evacuations, such as the egress components employed (i.e., stairs, elevators, etc.) and the strategies in use (phased evacuation, total evacuation, defend-in-place, etc.). In particular, a review is needed on the analysis of the studies concerning the evacuation through vertical transport and methods to encourage the use of elevators for evacuation. There is also the need to investigate if the use of different components has been studied individually or if there are attempts to investigate the combinations of different egress strategies.

Evacuation models are often used in the safety design process in the context of the performance-based design approach. They may be employed both to compare different safety designs as well as define the adequate egress strategies of a building. There is a subsequent need to review the state-of-the-art of the tools available and their applicability for the specific case of high-rise buildings. This review poses the following questions: are they suitable to provide qualitative and quantitative information on the impact of the use of different egress components? Are they adequate to compare different design solutions and relocation strategies? These are some of the questions that need to be studied further to achieve a better understanding on the capabilities of egress models for simulating high-rise building evacuation scenarios. This analysis is a fundamental step to evaluate the strengths and weaknesses of the current egress models and consequently identify the aspects that need further research studies.

\section{Objectives}

In order to answer the questions provided in the previous section, a set of objectives have been identified. The overall objective of this work is not only a literature review of 
human behaviour and modelling studies in the case of high-rise building evacuations. This review was a necessary step in a larger research project (Ronchi and Nilsson 2013) aimed at studying high-rise building egress strategies including both vertical and horizontal egress components by means of egress modelling.

A set of specific objectives are also defined and they correspond to:

(1)identify the key behavioural factors affecting the performance of people during a fire in a high-rise building, the singularities associated to this type of buildings and areas of future research.

(2) review the procedures and strategies currently adopted in high-rise buildings (e.g. horizontal and vertical evacuation methods, phased evacuation, total evacuation, defend-in-place, etc.).

(3) review and analyse the capabilities of evacuation models by reviewing their current characteristics and applications in the context of high-rise building evacuations.

The intended target audience of the review is all parties involved in the design and performance of high-rise building evacuation systems, such as fire safety engineers, architects, fire officers, etc. The present work addresses the absence of a review dedicated on the use of evacuation models and the study of human behaviour in high-rise buildings. In fact, previous reviews (Gwynne et al. 1999; Kuligowski et al. 2010) have investigated the capabilities of evacuation models without addressing the type of building under consideration.

\section{Methods}

A literature review was performed in order to achieve the objectives of this study. The first step was the definition of a number of keywords to ensure a systematic search in databases. The keywords included: high-rise building, tall building egress, emergency evacuation, evacuation strategies, evacuation elevator, stair evacuation. The literature was retrieved from different databases, primarily ScienceDirect (2012) [www.sciencedirect.com], Summon (2012) [www.serialssolutions.com/en/services/summon] and Evacmod (2012) [www.evacmod.net]. The material was integrated with relevant literature from colleagues and other publications/reports known to the authors prior to the review. Literature was included/excluded in relation to its relevance to the objectives of the review.

The material analysed can be divided into three main categories; (1) human behaviour in high-rise building fire evacuations, (2) egress components and strategies, and (3) modelling studies. The material collected contributes to the definition of the problems that need to be considered when analysing high-rise building evacuations and the assessment of the field of studies in which further research is required.

\section{Limitations}

This work focuses on the study of the use of different egress components for the fire evacuation of high-rise buildings by means of egress modelling. Due to the fact that the literature review is carried out within this context, it primarily addresses issues concerning evacuation and human behaviour in the event of fire and the application of egress models.

The study focuses on the most common building uses, namely office buildings, residential buildings (e.g., apartments, hotels) and health care facilities. According to Hall (2011), these building uses account for the most significant part of high-rise building fires. Nevertheless, other types of uses are possible (e.g., assembly, recreation, storage, etc.) and the associated design and behavioural issues may present different characteristics.

The literature is limited to high-rise building evacuation studies. This includes the analysis of human behaviour in fire, occupant relocation strategies and modelling studies. These topics are considered valid for an informed selection of evacuation models in the case of the study of different evacuation strategies in high-rise buildings. It should be noted that given the very broad scope of the review, in some places a detailed description is limited by the breadth of the analysis.

\section{Outline}

The first part of the review deals with the introduction of the problem and the objectives. In the second part of the review, the key factors associated with different uses of high-rise buildings are identified. The third part presents the issues about the use of different egress components. Egress components include the use of stairs, evacuation elevators, sky-bridges, and alternative means of escape (e.g., helicopter evacuation, etc.).

The fourth part provides the analysis of the evacuation strategies that can be employed to evacuate a high-rise building. The combined use of different egress components is described, with a particular focus on the joint use of evacuation elevators and stairs. The main strategies are analysed, namely total evacuation (i.e. simultaneous full evacuation), phased evacuation, defend-in-place, and delayed evacuation. Partial evacuation is here intended as a sub-set of total evacuation where only some floors are evacuated. The issues associated with people with disabilities are also described.

A review of the capabilities of the main evacuation models for simulating high-rise building evacuations is provided in the fifth part of the review. A set of previous examples of applications have also been described. In the sixth part, a discussion on the material that has been 
analysed in the literature review is presented. The last part of the paper provides suggestions on future research topics that need to be investigated.

\section{Behavioural issues associated with building use}

The impact of building use (and its subsequent design) on evacuation behaviour is addressed in this section. Three main categories of use have been identified:

1. Office buildings

2. Residential buildings (e.g. apartment, hotels, etc.)

3. Health care facilities

The building use affects several factors concerning the egress performance of a high-rise building such as the design, the characteristics of the population, the training of the population, the staff available, the fire safety installations, etc. Therefore, it represents one of the key factors influencing high-rise building evacuations (Hall 2011).

The study of the characteristics of the different types of high-rise buildings is crucial to understand the possible egress strategies to be adopted. For instance, the occupant on the upper floors could need to walk very long distances to reach the ground level. This may cause the need for rest periods during the evacuation and a subsequent additional increase in the evacuation times (Proulx 2001).

\section{Office buildings}

From a design perspective, office buildings have generally open floor plans, which limit the possibility of containing the fire within a compartment. Occupants are generally better prepared to evacuate the building since they are typically trained through evacuation drills and they are dressed, alert and responsible mainly for themselves (Proulx 2001). Occupants may be more familiar with the elevator egress component if elevator systems are used (Peacock 2009). Fire systems are generally wellmaintained, and may include recorded voice messages and fire alarms. Trained staff with particular responsibilities in a fire may be available on hand to facilitate evacuation.

\section{Residential buildings}

Residential buildings present completely different characteristics from both a design perspective as well as the characteristics of the population involved. Occupants may be asleep, not dressed, etc. (i.e., they are not ready to evacuate, thus causing a long delay in the start of the evacuation). Pre-evacuation times are therefore generally higher than other types of building occupancies (NFPA101 2012; BSI 2004). Different reasons may be the cause of long pre-evacuation times. Occupants may be emotionally tied to the structure and its contents leading to potential re-entry behaviours. Occupants may also be more reluctant to leave their own property for the same reason (Proulx 1995; Proulx 2001). In addition, information spread is slower due to compartmentation and social links can delay movement. Occupants are familiar with the environment in the case of apartments/dormitories, while they are not familiar with it in hotels. The population in hotels is in fact transient, causing possible difficulties in adopting the appropriate escape route in the case of fire. Compartmentation may offer defend-in-place options and fire safety designers may (or may not) consider those options as part of the strategy adopted in such type of buildings.

\section{Health care facilities}

Few studies have specifically addressed the issues concerning the last category considered here, namely health care facilities (named here HCF) (Frantzich 1996). In particular, the population in this type of environment presents different characteristics, involving people with temporary or permanent disabilities and mobility impairments. HCFs may have staff on hand (but number or ratios may depend upon the time of the day) but they also have a higher number of occupants that are not able to perform selfrescue activities (Sime 1987). The intrinsic characteristics of a high-rise building, i.e. long travel distances for people in the upper floors and vertical evacuations (e.g., the need for multiple elevator trips), demonstrate the importance of an effective egress strategy for this type of population. Many problems need to be addressed, such as the issues concerning fatigue, way-finding, use of vertical components (e.g. stairs, elevators), etc. These problems may be exacerbated in the case of a significant percentage of people with impairments (Christensen et al. 2006). The level of training of the staff becomes therefore another key factor in the evacuation performance of the building (Gwynne et al. 2010). From both an individual and group perspective, little research has been carried out in order to study the evacuation behaviours of vulnerable users, e.g., people with disabilities, elderly, etc., whose behaviour may strongly affect the egress performance of a building (Boyce and Shields 1999a; 1999b; Boyce et al. 1999; Hedman 2009; Hunt et al. 2012; Spearpoint and MacLennan 2012). These studies include the impact of disabled occupants on high-rise building evacuations and demonstrate the importance of this type of population in the calculation of the evacuation times (Shields et al. 2009; Koo et al. 2012). On the other hand, the variability of the possible impairments and the subsequent effects on occupant behaviours demonstrate the need for further studies on this topic (Ronchi et al. 2011).

A set of key discussion points can be identified in order to summarise this section on the impact of building uses 
on behavioural issues. Several high-rise building variants have been identified. These will influence evacuee performance and include:

- The impact of building uses on design and behaviours have been discussed

- OFFICE BUILDINGS. They generally present open floor concept design (compartmentation is difficult), occupants are prepared to evacuate. Fire systems are well maintained and staff is available

- RESIDENTIAL BUILDINGS: longer pre-evacuation times, occupants are reluctant to leave their property, compartmentation may be available.

- HEALTH CARE FACILITIES: presence of people with disabilities, staff training is crucial, possible availability of compartmentation.

\section{Egress components}

The evacuation process of a high-rise building is affected by the characteristics of the vertical egress components. Modern egress design should take into account several variables, including the change of occupant demographics (Spearpoint and MacLennan 2012), occupant behaviours (Nilsson and Jönsson 2011) and the advances in technologies that lead to the design of extremely complex buildings (and the subsequent increase in the building height). This section describes the main issues concerning the use of stairs, together with the alternative components that have been recently employed, e.g. evacuation elevators, sky-bridges, etc.

\section{Stairs}

The traditional method to evacuate such type of buildings is the use of stairs. The design of stairs may be based on different concepts. Stair width may be designed in order to provide an adequate capacity in the whole building in relation to the largest occupant load floor (Peacock et al. 2012a) or to accommodate the simultaneous evacuation of a given number of floors, e.g. 2-3 floors, given the case of a phased strategy. Different factors have been investigated, such as the design of the stairs in general, e.g., number of the stairs, stair width, staircase length, location in the building, etc. (Pauls 2005; Pauls et al. 2007) or their specific features, e.g., the slope of the stairs (Graat et al. 1999), the values for capacity on stairs (Pauls and Jones 1980; Pauls 1988), the impact of occupancy levels on stairs (Blair and Milke 2011), etc. These studies provide different methods to design stairs taking into account evacuation considerations.

Stair egress issues with regards to structural design are currently reflected in building codes, e.g., NFPA101 (2012), International Building Code (2009). Given structural criteria are met, apart from design issues, behavioural aspects should also be taken into consideration, such as ergonomics, motivation levels, group behaviours, etc. (Pauls et al. 2007). Gender or role may also influence evacuation performance from a behavioural perspective. For example, the experiments carried out by Boyce et al. (2009) showed that deference behaviours may arise during the evacuation process in stairs (e.g. male groups giving priority to women or groups with children, staff guiding other occupants, etc.).

Merging streams of evacuees in the floor-stair interface is another important factor during stairwell evacuations in high-rise buildings. The impact of merging behaviours can dictate the speed of the agents and consequently affect the total evacuation time. Galea et al. (2008c) suggested that in high-rise buildings, floors should be linked to the landing on the opposite side to the incoming stair in order to increase the efficiency of the flows. Boyce et al. (2009) discussed the merging ratios, performing experiments that show that despite differences in the geometric location of the door in relation to the stair, the merging ratio was always approximately 50:50.

Fatigue is another factor that needs to be investigated during stair evacuations in high-rise buildings (Choi et al. 2011). Investigations of actual accidents (Averill et al. 2005; Galea et al. 2008a) showed that evacuees may need to interrupt their journey due to fatigue, causing an additional delay in the evacuation process. This problem will become more evident over the years since the physical abilities of occupants is gradually reducing (due to changing demographics) (Spearpoint and MacLennan 2012).

Stair evacuations present significant issues regarding people with disabilities. Different evacuation problems have been analysed in the literature such as the ability of the occupants to use stairs with or without aid (Boyce and Shields 1999b), the impact on evacuation of the formation of groups with their assistors or others, (Shields et al. 2009), the use of dedicated stair devices (Adams and Galea 2011; Hedman 2009), etc. The variability of the possible impairments causes a relevant scatter in the behaviours of this type of occupant while using stairs and their movement speeds. The Americans with Disabilities Act (ADA) in buildings (ADA 2010) highlights the need for an adequate design taking into considerations all these issues which shall be an integral part of the safety design.

Several other aspects should be accounted for in the design of stairs. They include counter-flows (Kratchman 2007), presence or absence of fire-fighters during the stairwell evacuation, delays in the evacuation initiation (Peacock et al. 2009), etc.

The 9/11 WTC terrorist attack and several other high-rise building evacuations show the deficiencies of the safety designs (e.g., issues caused by the cross flow paths on the stairways between the fire-fighters and the 
WTC occupants (Torero et al. 2002)) that were relying only on stairs without taking into account all these aspects.

\section{Evacuation elevators}

The use of evacuation elevators has been the object of a great debate in the evacuation research community. Proulx (2009) stated that the effectiveness of using elevators for improving life safety has been demonstrated in a very early stage of evacuation research. Public awareness on the topic has been particularly raised by the evacuation issues showed by the $9 / 11$ terrorist attack of the WTC (Kuligowski 2011; Galea and Blake 2004; Zmud 2007). Elevator evacuation in buildings was the subject of research studies since the beginning of the 1930s (Bukowski 2009), Bukowski et al. 2009 but the WTC attack has pushed researchers and regulators to investigate the problem of vertical evacuation in a more systematic way.

The traditional concept that elevators should not be used during an emergency has been discarded by the need to ensure faster and effective methods to evacuate tall buildings. In particular, their possible use has been significantly prompted by the issues associated with the evacuation of people with disabilities using stairs. There are several problems concerning the use of evacuation elevators from a design perspective. The limited space in elevators may create issues related to the crush of the people involved, which may arise in restricted spaces and high density conditions (Harding et al. 2010). Flame, heat and smoke may invade the elevator shaft. In particular, while elevators move, negative pressure will suck smoke inside the elevator, creating the piston effect (Chien and Wen 2011; Klote 1983). Special requirements are also related to emergency power supply and water protection (Bukowski 2005; Bukowski 2010a; Bukowski 2010b). Evacuation elevators should be also designed to take into account earthquake protection, provision of emergency communication systems and resistance to the spread of contaminants (Klote et al. 1993). The pick-up locations should be in a floor that can be occupied by large crowds and be linked to the areas of refuge of the exit stairs (NFPA 2012; Weismantle et al. 2007).

The American Society for Mechanical Engineers (ASME) committee (ASME 2013; Klote et al. 1992b; Kuligowski and Bukowski 2004) that is responsible for elevator codes investigated the feasibility of the use of elevators during fire evacuations putting particular attention on human factors (e.g. the changes to the new section 2.27.10 in the 2013 edition of the occupant evacuation elevator operation requirements in ASME A17.1/CSA B44 (ASME 2013). Current building codes in the US (International Building Code 2009) and UK (BSI 2008) and recent research studies (Kuligowski and Bukowski 2004; Kinsey et al. 2009) have investigated these behavioural issues. The design of an egress strategy based on elevator use should therefore take into account not only the design problems of the emergency elevators but also the behavioural factors and their impact on the effectiveness of evacuation strategies. For instance, the willingness of the occupants to use elevators instead of the stairs in relation to the floor where occupants are located when the evacuation starts (Nilsson and Jönsson 2011; Heyes 2009; Kinsey 2011). Another advantage of the use of evacuation elevators as an additional egress component is that they can help people with mobility impairment to perform the evacuation without external aid (BSI 2008).

\section{Sky-bridges}

Alternative means of escape have been proposed for the design of high-rise buildings. One of the possible methods is the introduction of a horizontal evacuation means at height, i.e. the use of sky-bridges to link towers. This egress component can be a design solution in the case of buildings comprising at least two towers. The sky-bridge concept is not new. The first sky-bridge was the Ponte dei Sospiri, designed by the architect Antonio Contin in Venice at the beginning of the $17^{\text {th }}$ century (Wood et al. 2005). In recent times, this design solution has been already implemented in several buildings around the world, e.g., the Petronas Towers in Malaysia (Ariff 2003).

Sky-bridges can be employed in order to evacuate occupants at a level different than the ground floor. However, the feasibility of this design solution is linked to several factors, such as the height of the building and its general design. The immediate benefit deriving from the use of sky-bridges is the reduction of the vertical evacuation travel distance and the increase in the options available for the evacuation. Nevertheless, the effectiveness of a skybridge is strictly linked to the evacuation strategy adopted and the other egress components available (Wood 2007). The placing of the sky-bridges should be done to ensure the maximum efficiency of the egress circulation and then to benefit evacuation. For this reason, a sky-bridge should be placed at a level where there is the lift zoning changeover (Wood 2003). In addition, it should be placed in a position between the higher and lower floors of the building, since otherwise the majority of the occupants would need to travel significant distances through vertical means of escape (Wood et al. 2005), taking into account also the expected occupant load of the different floors (Wood 2003). The use of a sky-bridge would also have a significant impact on the planning of the building since the connection floors would become sky-lobbies (i.e., including stair and lift lobbies) (Wood 2003). There is currently a lack of knowledge about the effectiveness of sky-bridges 
during evacuation and studies addressing their use in combination with other egress components are required.

\section{Refuge floors}

Refuge floors are floors designated for holding occupants in a building and their effectiveness has been the object of dedicated studies (Ming Lo and Will 1997). Recent regulations, such as the Hong Kong Fire Safety Code (Hong Kong Building Department 1996), prescribe the introduction of refuge floors in the design of the means of escape. From an evacuation perspective, refuge floors present several advantages: (1) they are a place of rest for the evacuees, (2) the possibility of having stairs or lift shafts filled with smoke is reduced, (3) they can be employed to protect people with disabilities and/or injured evacuees (Williamson and Demirbilek 2010), (4) they can be used as a command point for rescue teams to assist evacuation, and (5) they can serve as a fire-fighting base (Wood 2007). In addition, the use of evacuation lifts would be made easier since refuge floors may serve as pick up floors since they could accommodate a significant number of evacuees (Wood et al. 2005). On the other hand, there are factors which may cause the failure of the refuge floor concept, e.g., human behaviour issues (e.g., overcrowding, under-utilisation, occupants' fear of remaining in a threatened structure, etc.), evacuees actions, cost effectiveness in comparison with alternative design solutions, sustainability, etc. (Clawson and O'Connor 2011).

\section{Alternative means of escape}

Further suggestions for alternative means of escape are available in the literature. An example is the use of helicopters to perform rescue operations. For example, this solution was adopted during the evacuation of the WTC in 1993 (USFA 1993). Some international regulations prescribe mandatory helipads for high-rise buildings such as the Indian Fire and Life Safety Code (Bureau of Indian Standards 2005). Nevertheless, helicopter rescue procedures are extremely dangerous and there are no standards in the U.S. and in most countries outside the U.S. about their implementation. The landing procedures and the rescue operations are in this case very dangerous due to the air turbulence (Biava et al. 2012) and updrafts caused by smoke and heat.

Another example of alternative means is the use of facades in emergency exiting (Romano 2003) or inflatable ejection modules (Khanna 2003), parachutes, ropes, slides, or temporary elevators connected to the sides of the building. For example, although the use of evacuation chutes is common for evacuation from ships and planes, this solution could be impractical for any long distance. Wood (2007) pointed out that this type of systems have been met with almost universal scepticism from the practitioners due to the low technical detail of the solution proposed if compared with the use of evacuation elevators.

A set of key points have been identified to summarise this section on the egress components under consideration:

- STAIRS: Traditional method to evacuate high-rise buildings. Research has investigated many factors, including both design and behavioural issues. Main factors needing further research includes the impact of fatigue and people with disabilities on evacuation

- EVACUATION ELEVATORS: potential use for high-rise buildings, design problems, e.g., the piston effect, behavioural issues associated with under-utilisation, useful for people with mobility impairment

- SKY-BRIDGES: horizontal egress means at height, they reduce travel distances, occupant behaviours need further studies

- REFUGE FLOORS: advantages include the help of people with disabilities, a location of rest for occupants and command points for fire-fighters, the risk for stack effect is reduced. Disadvantages include economic effectiveness, under-utilisation, overcrowding

\section{Egress strategies}

The design of the egress components is only the first step towards the achievement of an adequate level of high-rise building safety. Relocation strategies play a fundamental role in the safety design (Tubbs and Meacham 2009). Efficient evacuation is a combination of moderate speed and moderate densities (Pauls 1994). Few studies have investigated the issues concerning the combination of different egress components, such as occupant behaviours in the case of a combination of stairs and evacuation elevators (Nilsson and Jönsson 2011; Heyes 2009; Kinsey 2011). For this reason, there is a need to review the current findings on this topic in order to direct possible future research studies and to improve the current understanding of the state-of-the-art. In addition, the choice of the appropriate strategies in presence of alternative means of escape (e.g. sky-bridges) has not been investigated systematically (Lay 2007).

During a fire emergency, the standard procedure is to evacuate downwards in a building. There could be exceptions in the case of untenable conditions in the lower floors, which may lead to evacuate to the roof. However, this strategy is not advisable if not strictly necessary because of the limited space in the building roof and difficulties in the rescue procedures of the occupants, e.g. the use of helicopters for evacuation (See Alternative means of escape section) and the additional occupants' effort required to climb stairs. This strategy is currently rarely adopted systematically for three main reasons, 
namely (1) air turbulence generated by the helicopters together with the smoke and heat coming from the building increase the risk of performing unsuccessful landing and rescue operations (Biava et al. 2012), (2) the number of people that can be rescued through this strategy is rather limited if compared with the population of a high-rise building, (3) mobility issues linked to fatigue, people with disabilities, etc. would be worsened by the process of evacuating the building upwards (Shi et al. 2009).

The main egress strategies can be summarised into four main approaches, namely (1) total evacuation (or simultaneous full evacuation), (2) phased evacuation, (3) defend-in-place and (4) delayed evacuation. The possible application of different strategies is mainly dependent upon the characteristics of the building in general (e.g., egress components available, compartmentation, etc.), the population involved, the staff/rescue operators and the nature of the scenario and the hazard involved.

\section{Total evacuation}

This strategy involves the evacuation of all building occupants at once from a building to the designated area of safety (Hassanain 2009). To date, the 09/11 terroristic attack of the WTC is one of the main case studies in which total evacuation occurred (Averill et al. 2005). The possible large population involved in the evacuation of a high-rise building may cause significantly high densities in the means of escape. This is strongly dependent on the building use (see Behavioural issues associated with building use section) that will be a key factor in the occupant load of the building as well as the behaviours of the occupants. This type of evacuation strategy is generally ordered by the fire department (and in this case it may not be a planned response) or it could be the result of a spontaneous decision of the population of the building. The spontaneous behaviour of leaving a hostile environment has been observed first by Wood (1972), who studied more than 950 fires to understand evacuees' behaviour. This behaviour might lead the evacuees to discard defend in place strategies; however, it may be frustrated by the high-rise building layout which often requires long travel distances to reach a safe area. Another issue is that in most high-rise building fires, part of the evacuee population may not be directly exposed to a hazard due to the vertical compartmentation and size of the structure (Peacock et al. $2012 b)$. High congestion levels in the means of egress may also lead to an increase in the time to evacuate the building. Faster evacuation may instead occur in the case of a reduction in response times and low congestion (the cases with lower occupant loads, e.g. apartment blocks).

\section{Phased evacuation}

There are scenarios in which the single staged total evacuation is not practical. In the case of staged total evacuation, some occupants may be asked to remain in the building for a certain period of time in order to optimize the flows (Pauls 1994). Those occupants might feel discomfort in remaining in a threatened environment. In addition, when high-density conditions occur in a bottleneck, the maximum flow capacity may drop (Cepolina 2009). The phased evacuation strategy is based on the concept that occupants in the most critical floors such as the fire floor and floors nearby will be prioritised. This strategy is adopted in order to decrease the queuing time in the egress components and reduce people densities in the means of escape. The fire compartmentation plays a key role in this strategy (The Building Regulation 2006). In fact, occupants in the compartment of the fire need to be evacuated, whilst the remaining occupants need to be evacuated only if it is necessary. The effectiveness of this strategy relies also on the fire safety installations available in the building, the level of training of the staff and adequate means of communication within the building (Wong and Luo 2005).

An example of such a strategy is the procedure employed in the Petronas Towers (Ariff 2003). In the case of an emergency contained on only one floor, occupants on three floors need to be relocated, namely the fire floor, the floor above and the floor below the fire. Occupants will empty that floor and they need to re-enter the building three floors below their floor in what is called a "temporary refuge floor". These occupants will wait for instructions in accordance with the development of the situation (e.g. whether a total evacuation is needed, etc.). Similar procedures are employed in other high-rise buildings all around the world, such as the Prudential Tower in Boston (Boston Properties 2012).

\section{Defend-in-place}

A possible solution to be adopted in the case of a high-rise building fire is the defend-in-place strategy. Occupants should shut the door of their room and wait for the rescuers. This strategy has been employed in the past for people with disabilities since they may present mobility impairments which may prevent them from performing self-rescue activities. Several case studies are in support of this strategy, such as the recent apartment fire in Rinkeby (Andrée and Bengtson 2012). Many of these fatalities may have been avoided if this strategy would have been adopted (Proulx 2001).

Proulx (2001) stated that the defend-in-place strategy is the most appropriate behaviour during high-rise building fires in the case of residential buildings (e.g., dormitory, hotels, apartments, etc.) if they have the following main characteristics from both the occupants and the design 
point of view (See also Residential buildings section): (1) the number of floors of the building is above 6 floors since evacuation of low-rise buildings is faster in that case, (2) the building is residential, including enclosed compartments where tools for defend-in-place activities are available, (3) the building is made of non-combustible construction, (4) an alarm system informs occupants of the occurring fire, and (5) a voice communication system provides occupants with information about the evolution of the fire and advises occupants on the defend-in-place activities to perform. The effectiveness of this strategy is in fact strongly affected by the level of communication between the occupants and the rescue operators. Actual incidents such as the recent fire at the Kuddbygränd 12 in Stockholm (Swedish Accident Investigation Board 2010) resulting in 7 fatalities showed that a lack of information about the actions to be performed by the occupants could be one of the main causes of the failing of this strategy (i.e. occupants did not remain in their apartments and they eventually died in the staircase).

\section{Delayed evacuation}

A delayed evacuation takes place when evacuees are temporarily waiting in dedicated areas of refuge/rescue assistance (e.g., refuge areas, refuge floors, etc.) in order to be reached by rescuers. In this case, the term delayed evacuation is intended as a deliberate delay in the evacuation as a part of an evacuation strategy. This type of strategy is generally employed to rescue occupants with temporary (i.e. injured) or permanent disabilities. These occupants may not be able to perform self-rescue activities and may need an external aid to reach a safe place. In particular, most of the disabled occupants may not be able to use stairs, with a subsequent need for help in the case where this egress component represents the only means of escape available. For this reason, this strategy seems to be particularly effective for high-rise buildings with a significant percentage of this type of users, e.g., health care facilities. The space available for the evacuation is another factor in support of the use of this approach.

Different examples are available in the literature, such as the compulsory introduction of refuge floors in the Hong Kong legislation context (Hong Kong Building Department 1996) in order to provide a safe area for people with disabilities, injured evacuees, etc. and perform delayed evacuations or the Swedish Legislation (BBR 2012) where temporary evacuation locations, i.e., refuge areas, are required for specific building uses and conditions.

\section{Use of egress components}

Egress strategies may include the use of one or more egress components. Table 1 presents a schematic description of
Table 1 Use of egress components in relation to different egress strategies

\begin{tabular}{|c|c|}
\hline Egress strategy & Egress component(s) \\
\hline \multirow[t]{7}{*}{ Total evacuation } & - Stairs \\
\hline & - Elevators \\
\hline & - Stairs + Elevators \\
\hline & - Stairs + Sky-bridges \\
\hline & - Stairs + Elevators + Sky-bridges \\
\hline & - Stairs + Elevators + Sky-bridges + Refuge floors \\
\hline & $\begin{array}{l}\text { - Alternative means of escape (+other } \\
\text { component(s) depending on the mean of escape) }\end{array}$ \\
\hline \multirow[t]{7}{*}{ Phased evacuation } & - Stairs \\
\hline & - Elevators \\
\hline & - Stairs + Elevators \\
\hline & - Stairs + Sky-bridges \\
\hline & - Stairs + Elevators + Sky-bridges \\
\hline & - Stairs + Elevators + Sky-bridges + Refuge floors \\
\hline & $\begin{array}{l}\text { - Alternative means of escape (+other } \\
\text { component(s) depending on the mean of escape) }\end{array}$ \\
\hline \multirow{2}{*}{$\begin{array}{l}\text { Delayed } \\
\text { evacuation }\end{array}$} & - Stairs + Refuge floors \\
\hline & - Stairs + Elevators + Refuge floors \\
\hline Defend in place & - Refuge floors (areas of refuge) \\
\hline
\end{tabular}

the use of different egress components in relation to different egress strategies.

The traditional evacuation strategy for high-rise structures relies on the use of stairs. As pointed out in previous Stairs section, several issues have been investigated with regards of the stair design. The basic concept is to ensure that the strategy adopted is able to safely evacuate the population of the building trying to avoid overcrowding. Current legislation provides a range of guidance on the design of stair layout, e.g. the NFPA 101 in the US or the Approved Document B in the UK.

Recent studies have investigated the importance of an appropriate egress strategy when using evacuation elevators. Actual evacuation scenarios showed that elevators can be used to assist the evacuation of a high-rise building (Averill et al. 2005; Sekizawa et al. 1999). Unfortunately, few studies are available on the human factors associated to the use of this egress component (Heyes 2009; Kinsey 2011; Nilsson and Jönsson 2011). Current practices require a management system able to dispatch an elevator trip aimed at emptying the whole shaft height (Weismantle et al. 2007). The number of the elevator stops is another key factor to be considered. Any attempt to counteract the delay due to the increased number of floors served by the evacuation elevators is currently not considered acceptable in normal lift usage theory (Barney 2003). The main solution generally employed is to serve a maximum of 
approximately 15 floors with one elevator or a group of elevators (Noordermeer 2010). The concept of zoning is therefore necessary to optimize the design solution employed. The building is therefore divided into zones of a certain number of floors where elevators have been assigned. Kinsey et al. (2012) investigated the main human factors associated with the use of different lift strategies, with a particular emphasis on the under-utilisation of elevators in relation to accepted waiting times. High-rise buildings are also generally provided with shuttle elevators that are usually larger and faster, whose aim is to link sky-lobbies. The concept of "lifeboats" was proposed by Pauls (1978) in the 1970s. He made a comparison to a ship evacuation where occupants are gathered before leaving the ship using lifeboats, i.e., a mustering approach. He suggested that occupants could initially evacuate to the sky-lobbies and then wait there for further instructions.

A few studies have investigated the combination of different egress components. First studies about the combined use of these egress components were already available in the 1970s (Bazjanac 1977; Pauls 1978). Bazjanac performed the first evacuation simulation considering elevators, while Pauls' work was based on hand calculations. Pauls provided predictions of evacuation times in a high-rise building by using different types of means of egress (either stairs or elevators) and different layout of the egress components employed (essentially varying the width of the stairs).

During the 1990s, the studies made by Klote et al. (1992a) were focused on investigating the feasibility of using evacuation elevators by comparing the evacuation times obtained employing different egress components. The combined use of stairs and elevators was also investigated and the conclusions stated that evacuation elevators may represent a substantial improvement in the safety design of high-rise buildings. In particular, Klote found, using egress modelling, that taller buildings are subjected to an increased reduction in the evacuation times in the case of use of evacuation elevators (Klote et al. 1992a).

Studies are available in the literature with regards to the human factors associated with the use of elevators. They are either based on an online survey and computer simulations (Kinsey et al. 2009; Kinsey 2011), on-site questionnaires (Jönsson et al. 2012) or simulation questionnaires and an online survey (Heyes 2009). They investigated the risk perception of the evacuees in terms of their choice of using a certain egress component (i.e., elevators or stairs) in relation to their position with respect to the fire. Levin and Groner (1994) investigated human factors associated with the use of elevators in the context of air traffic control towers evacuations.

All studies confirmed that an increasing number of occupants are likely to use elevators to evacuate from a high-rise building with increasing floor height. Results found by Heyes (2009) and Jönsson et al. (2012) provide correlations for floors respectively from 5 to 60 (Heyes 2009 ) or 5 to 24 (Jönsson et al. 2012). The online survey made by Kinsey (2011) was used to perform a regression analysis of the correlation between lift/stair in relation to the floor where the occupants are located. The floor range considered is from 5 to 55 . The above mentioned research studies reveal that building occupants would be prepared to use evacuation elevators if they are given sufficient training. Nevertheless, Heyes (2009) stated that a number of participants were reluctant to use elevators even from the $60^{\text {th }}$ floor of a high-rise building.

Another key aspect to be considered is the time that an evacuating population would be expected and willing to wait. This consists of the likelihood of the occupants waiting for an emergency elevator before deciding to use the stairs. This is a crucial factor in the vertical evacuation process of a high-rise building but unfortunately the studies that address this issue are scarce (Nilsson and Jönsson 2011). Heyes (Heyes 2009) and Kinsey (2011) shows the dependency of the waiting time to the floors where the occupants are located. The data suggests that almost all the occupants are not willing to wait for elevators more than 10 minutes. The difficulties of collecting this type of information derive from the need to have data that actually reflect the real behaviour of people in a fire event. The specific layout of the infrastructure under consideration together with the warning messaging strategies employed to encourage the use of the elevators also play a fundamental role (Kuligowski and Hoskins 2012).

An understanding of human behaviour regarding the use of the egress components is crucial during the calibration of a model input. Modelling studies and relocation strategies should take into account that the split of occupants using the two different egress components should be carefully evaluated in relation to the choices that people would make in a real-world scenario. Realtime information, e.g. the elevator waiting time, etc., should therefore be provided to the occupants in order to influence the evacuation performance of a high-rise building (Klote et al. 1993; Kuligowski and Hoskins 2012). Occupants could in this manner perform an informed decision on the egress component to use and become more likely to choose to use the elevators. The importance of a correct messaging strategy has also been highlighted by the recent studies made by Kuligowski and Hoskins (2012). They pointed out that there are no standard requirements or widely recognized guidance for the messages about the use of emergency elevators, both for building occupants and emergency responders.

The greater challenge of a joint use of stairs and elevators relies on the strategic planning, interface design and operator training (Groner 2002). The prediction of the people performance is made even more difficult in the case of additional alternative means of escape. They 
could turn out to be inadequate if not accompanied by detailed evacuation plans. An example is the evacuation of the Petronas Towers due to the bomb scare on the day after the WTC terrorist attack in 2001 (Ariff 2003). This building consists of two towers, three stairwells and thirty-nine elevators using a double-decker design. Elevators are designed in a manner that if one lift got stuck, another elevator might move along and the occupants can move to the other one. The towers also have a sky-bridge at floors 41 and 42 as an additional egress component. In the case of a single tower evacuation, occupants on the upper floors can evacuate one of the two towers by using the stairs until they reach the floor of the sky-bridge. They can eventually use the elevators to reach the ground floor from the other tower. Occupants below the sky-bridge would instead use the stairs. Since there was no information about the location of the bomb, the occupants of both towers tried to cross the sky-bridge at the same time, causing heavy congestion and counter-flows which resulted in a jam (Ariff 2003) which caused a significant delay in the evacuation time (i.e. the evacuation took a number of hours). The same building was evacuated in October 2002 using a new and more effective strategy that employs shuttle elevators servicing the sky-lobbies in both towers (Bukowski 2010b). The outcome was a substantial reduction in the evacuation times (about 32 minutes were needed), which highlighted the importance of an efficient evacuation plan.

An efficient use of combined egress components is not trivial and requires high efforts from the management point of view and a deep knowledge of the specific characteristics of the building under consideration. In this context, the use of evacuation modelling tools may be appropriate in order to evaluate the effectiveness of possible evacuation strategies. The review of the previous studies available on the topic has therefore been presented in next Model capabilities and modelling studies section.

A set of key points have been identified in this section on the egress strategies currently used in engineering design:

- TOTAL EVACUATION: significantly high densities may occur, efficiency depends on the building use and occupant load, it could be spontaneous or ordered by the fire department

- PHASED EVACUATION: most critical floors are evacuated first, fire compartmentation has a key role, staff and occupant level of training is fundamental

- DEFEND-IN-PLACE: suitable for people with disabilities and generally for residential buildings, communication strategies are critical

- DELAYED EVACUATION: relies on areas of refuge, suitable for people with disabilities

\section{Model capabilities and modelling studies}

The previous sections investigated the behavioural issues associated with the use of the main egress components and strategies in high-rise buildings. The safety design of high-rise buildings may rely on different methodological approaches, driven by the type of legislation used by the designer (i.e., prescriptive based or performance based). In particular, performance based design can make use of evacuation models for the assessment and design of building safety (Tavares 2008). The flexibility and relative user-friendliness of this type of tool along with changes in the regulatory codes led to their increased use in performing fire safety design assessments and analysing different relocation strategies. The characteristics of evacuation models are rapidly evolving since the model developers constantly include new features and sophisticated sub-models. This is mainly done to encourage model users to apply evacuation models in different fields and increase the number of model users (Ronchi and Kinsey 2011).

There are currently six main evacuation model reviews useful for the definition and characterisation of the evacuation model capabilities (Friedman 1992; Gwynne et al. 1999; Kuligowski et al. 2010; Olenick and Carpenter 2003; Santos and Benigno Aguirre 2004; Watts 1987). The most important and recent review of evacuation models has been provided by Kuligowski et al. (2010) in which 26 models are included. The review includes a detailed categorisation of the model features as well as the definition of the modelling methods to represent model agents, sub-algorithms, validation methods, etc.

As pointed out by Kuligowski et al. (2010), there are different problems concerning this type of evacuation model review. The key problem is related to the rapid advances in the evacuation model capabilities which make it difficult to provide up-to-date information. The framework of Kuligowski's review has been recently employed to create an online platform (it can be found at www.evacmod.net) in which model developers provide up to date information about models on the site themselves. The information about evacuation models included in this study was therefore retrieved from this model directory.

As discussed in the previous sections, the characteristics of different models need to be reviewed in order to check their suitability for simulating high-rise building evacuations. In this context, two type of analyses have been provided, namely 1) to review the main characteristics of a set of the most common evacuation models in order to identify the features that need to be embedded within them for simulating high-rise building evacuation scenarios, (2) to analyse the literature about the main studies available about the use of evacuation models for high-rise buildings. 


\section{Review of model capabilities for high-rise building evacuations}

The first categorisation that needs to be discussed when studying evacuation model capabilities is the method employed to represent the movement of the occupants. This is important in order to understand the assumptions employed by the models and assess their impact on model outputs. According to Kuligowski et al. (2010), models can be divided into three groups, namely 1) coarse network models, 2) fine network models, and 3) continuous models. These three types of methods represent a different level of resolution in the representation of the behaviours of the agent.

In the coarse network models, the space is represented as a network of nodes and arcs, representing different parts of the infrastructure (e.g., rooms, stairs, etc.). This is the simplest method to simulate an evacuation scenario and it presents advantages and limitations. The main advantage is that they have fast computational time (which might be particularly valuable) even in the simulation of very complex evacuation scenarios such as the evacuation process of a high-rise building. The main limitations are related to the simple representation of the evacuation which does not include many of the behaviours that may occur during an evacuation. A recent survey about the model users performed by Ronchi and Kinsey (2011) showed that this approach has been abandoned by a significant part of model developers and model users, i.e. there are no models using this approach in the seven most used models.

The fine network approach represents the space as a grid of uniform cells. Each cell can be occupied by one occupant at a time. The movement of the agents is simulated within those models through a series of steps between the cells of the network. A common feature of these models is an improved tracking of the location of the occupants during the evacuation process based on a fine network representation of the space in comparison with coarse network models. Agents are modelled as individual entities with the possibility of simulating complex local and global behavioural factors. This type of model is widely employed and examples of their applicability for high-rise buildings will be provided in next Modelling case studies section.

Continuous models simulate the agent movement on a coordinate system within the environment. Continuous models re-calculate the coordinates of the agents at every time-step in order to depict their movement. They offer the flexibility to simulate occupant behaviours which may be sensitive to occupant location, orientation and interdistance among the agents. These features are important to simulate high-rise building evacuations, in particular for the case where high population densities arise, since continuous models are not sensitive to the type and characteristics of the network employed (Nilsson 2007). The main disadvantage of these tools is the computational time needed to simulate complex scenarios, i.e. generally higher than the time needed with fine and coarse node models.

A key factor for assessing the suitability of different evacuation models for the simulation of tall building evacuations is their ability to represent different egress components and the evacuee interaction with them. According to the discussion in Egress components section, models should be able to simulate both horizontal and vertical egress components if they are to represent the range of viable procedures employed. In this context, it is important to assess if models are able to simulate emergency elevators. The specific need for elevator modelling is caused by many factors, such as possible long travel distances involved in high-rise building evacuations. In fact, long distances make the use of elevators more likely which then in turn requires elevator modelling capabilities to assess egress procedures which employ them. The complex decision making process associated with the use of elevators in the case of multiple egress components available should also be addressed by the models.

A set of evacuation models is examined in this section to provide an analysis of their characteristics and their suitability for simulating high-rise evacuation scenarios including multiple egress components. These models are all listed in the seven most used models in the recent survey performed by Ronchi and Kinsey (2011), namely STEPS (Mott Macdonald 2011), Pathfinder (Thunderhead Engineering 2011), buildingEXODUS (Galea et al. 2004), FDS+Evac (Korhonen and Hostikka 2010) and one model that was selected since it was specifically designed for high-rise building evacuations, i.e., EXIT89 (Fahy 1996). In addition, simulation tools with specific features have also been reviewed, such as ELVAC (Klote and Alvord 1992), ELEVATE (Peters 2002), Building Traffic Simulator (BTS) (Siikonen 1993) (developed for modelling vertical evacuations) and BUMMPEE (Christensen and Sasaki 2008) (developed for modelling mixed-ability populations).

The selection of the models is based on their scope (i.e. if they are designed for simulating high-rise buildings, the population that can be simulated, etc.), and the egress components that they can represent (e.g., stairs, elevators, etc.). The focus of this section is on their degree of sophistication in representing vertical egress components. In particular, the models are reviewed in terms of their capabilities in simulating emergency elevators and the interactions with other egress components. The simulation of emergency elevators is analysed in terms of kinematic (e.g., acceleration, speed, etc.), physical (e.g., maximum load, number of doors, etc.), operational (e.g., opening and closing times, floor 
range specification, etc.) and behavioural (e.g., implicit or explicit representation of waiting times, choice of the egress components, etc.) features.

EXIT89 (Fahy 1996) is a freeware coarse network model available from the model developer. EXIT89 has been reviewed since it has been specifically designed for modelling high-rise building evacuations and it has been recently applied during the analysis of the World Trade Center evacuation (Kuligowski et al. 2011). The limitations and advantages associated to coarse network models make EXIT89 a model that can be relatively fast to set up and able to rapidly produce results in a short computational time in comparison with other models. On the other hand, since the model was developed when the use of emergency elevators was not common, it does not allow the simulation of this egress component. It is therefore considered not suitable for simulating high-rise building evacuations including elevators.

STEPS (Simulation of Transient and Pedestrian movementS) (Mott MacDonald 2011) is a fine network model developed by the Mott MacDonald simulation group. The model is a commercial tool freely available for educational purposes. The movement towards the exits is calculated through the use of a potential map. STEPS also allows the user to define specific routes through the use of checkpoints. The agents are represented through a list of factors which include unimpeded walking speeds, awareness, patience, and pre-evacuation time. The exit route of the agents is based on the agent's patience coefficients in order to represent their likelihood of waiting in a queue. Evacuation elevators can be represented within the model through a series of attributes concerning the kinematic, physical, and operational aspects of the vertical evacuation. Behavioural performance is represented automatically by the model with no explicit user control of how many agents will use an elevator on a given floor or their waiting time for the elevators. Nevertheless, these behaviours can be represented implicitly, e.g., through the use of waiting zones, patience coefficients, etc. The main advantage of the model is the representation of the interactions between horizontal and vertical components. The limitations are associated with the implicit representation of the behavioural factors associated to vertical egress components and the problems deriving from the use of a fine network approach (e.g., case studies with high densities may be dependent on the grid employed).

Pathfinder 2011 (Thunderhead Engineering 2011) is a continuous model. The model is a commercial tool developed by Thunderhead Engineering freely available for educational purposes. The model uses two different methods to simulate people movement. The first is a hydraulic model, the SFPE method by Gwynne and Rosenbaum (2008), based on the calculation of the means of the capacity of the considered environment.
The second methodology is an agent-based model, i.e. the Reynolds (1999) steering behaviour model refined by Amor et al. (2006). The steering system moves passengers along their paths and allows each occupant to interact with the environment and the other occupants. Emergency elevators include user-defined kinematic, physical, and operational features. The latest version of the model includes a way-scripting function that enables the occupants to be directed by performing "go-to" or "wait" actions. This command can be used to implicitly represent the decision making process of the occupants choosing between different vertical components (the model includes indeed an elevator sub-model). The main advantage of this model derives from the possibility to represent the interactions between vertical and horizontal egress components. Limitations are associated with the limited number of input parameters in the elevator kinematic sub-model (e.g., it does not include motor delay, deceleration rate, deceleration jerk, etc.).

buildingEXODUS 5.0 (Galea et al. 2004) is a commercial tool developed by the Fire Safety Engineering Group at the University of Greenwich. It is a fine network model using a two-dimensional grid of nodes with the motion and behaviours determined by an individual set of heuristics of rules. The emergency elevator submodel is currently under development and it is still not officially released. It includes kinematic, physical, operational and behavioural features. The elevator sub-model embeds a detailed mechanism to control the floor dispatching process during the simulation. The model embeds a set of agents attributes to be assigned in order to simulate the behaviours of the agents, namely (1) choice of the egress component (i.e., elevator or stairs), (2) assessment of the initial elevator area, (3) elevator wait behaviour, and (4) elevator redirection (i.e. use stairs instead of elevators). Default settings are mainly derived from an online survey performed by the model developers (Kinsey 2011). The main advantage of this model is its flexibility in representing complex relocation strategies and the behavioural variables embedded. Limitations are associated with the general problems of fine network models (e.g. results may be dependent on the grid size employed in the case of high-densities) and the need for behavioural data to calibrate the model input.

FDS+Evac (Korhonen and Hostikka 2010) is an open source continuous model developed by VTT in Finland. FDS+Evac treats each agent as an individual entity, using stochastic properties for assigning their main characteristics, such as unimpeded walking speed, pre-evacuation times, familiarity with the exits, etc. The models present many functions and variables that could permit simulating elevators artificially although the current version of the model (2.3.1) does not embed an elevator sub-model. Nevertheless, an elevator sub-model is currently under 
development (being already embedded in the source code) and it will be released together with the next version of the corresponding fire model FDS, the Fire Dynamics Simulator by the National Institute of Standards and Technology (McGrattan et al., 2008). Unfortunately, while documentation is available for all the elevator sub-models described, to date FDS+Evac developers have not provided documentation on their elevator sub-model. The main advantage associated with FDS+Evac is its great flexibility in simulating complex agents' behaviours. The main limitations are linked to the high computational time required to simulate a complex high-rise building and the considerably high time required for the input set-up. For all these reasons, the current version of the model is not considered as suitable to simulate complex high-rise building evacuations including multiple egress components.

A set of dedicated tools to perform vertical transport evacuation modelling is also available, e.g., ELVAC (Klote and Alvord 1992), ELEVATE (Peters 2002), Building Traffic Simulator (BTS) (Siikonen 1993). The main limitation of these tools is that the simulated human factors are generally homogeneous and simplified (Kinsey 2011). In addition, since the models are specifically designed for vertical evacuation modelling, the interactions between horizontal and vertical egress components are represented implicitly. For example, ELVAC includes a "trip inefficiency" component in order to represent additional and/or suboptimal elevator time components (i.e. time needed to empty floors and trips to pick up latecomers). ELEVATE and BTS assume that the bottlenecks are placed around the vertical components and exits, i.e., behaviours outside these areas are represented implicitly through varying arrival rates to the vertical components. Dedicated studies are needed to evaluate the possibility of using these models in conjunction with egress models. Given the current state of the art, these models alone are not considered suitable for analysing scenarios involving both horizontal and vertical components.

The combined use of vertical and horizontal egress components may generate safety design issues associated with a population including disabled occupants. This is reflected in the need for dedicated research on the subject. For instance, a recent study was aimed at developing an evacuation model entirely focused on the simulation of the impact of disabled people on evacuation, namely the BUMMPEE (Bottomup Modeling of Mass Pedestrian flows - implications for the Effective Egress of individuals with disabilities) model (Christensen and Sasaki 2008). The focus of this model is to simulate behaviours which represent the diversity and prevalence of disabilities in the population and their interaction with the infrastructure and the environment. Research activities on the validation of this model are currently being conducted but initial studies applying the model for high-rise buildings are already available in the literature (Koo et al. 2012).

\section{Modelling case studies}

This section reviews a set of relevant studies performed to analyse high-rise building evacuation scenarios through computer modelling.

The most high profile evacuation study available in the literature involving the evacuation of a high-rise building is without any doubt the evacuation of the World Trade Centre in 2001. Evacuation models have been employed to reconstruct the evacuation process and assess the key variables affecting the egress performance of the building.

Galea et al. (2008b) used buildingEXODUS to approximate the evacuation of the North Tower of the WTC. The study used the response data obtained by the survivor accounts (Blake et al. 2004) and the population of the building is derived from the formal investigation made by the National Institute of Standards and Technology (Averill et al. 2005). The model results suggested that the impact of fire-fighters entering the building on the overall evacuation efficiency was minimal. Different hypothetical scenarios were also simulated, permitting to draw conclusions on, (1) the importance of having dispersed staircases within buildings, (2) the importance of having a balanced distribution of occupants in the staircases in the case of high-rise building evacuations, (3) the change in evacuation efficiency in high-rise buildings (the average floor evacuation efficiency decreases with height). The simulation work also highlighted three fundamental components of high-rise building evacuations that are not currently fully represented in evacuation models, namely (1) the impact of fatigue, (2) the impact of group dynamics and (3) the impact on evacuation dynamics of disabled people. The importance of the behaviours of this type of occupants in the WTC and the subsequent effects on the evacuation process has been fully discussed by Shields et al. (2009). Evacuation models need to take into account the possible simulation of not only mixedpopulation but also the global impact they may have on the evacuation process, e.g., their need for assistance, the formation of emerging groups with their assistors or others, etc. Johnson (2005) performed a study when he reviewed existing computer models with a critical point of view deriving from the WTC evacuation. He pointed out several aspects that need to be addressed in evacuation models, such as (1) the impact of the ingress/egress of emergency personnel, (2) the representation of more complex group dynamics, and (3) the impact of building information and management systems on the evacuees' ability to evacuate.

Kuligowski et al. (2011) used 4 evacuation models, namely EXIT89 (Fahy 1996), Simulex (IES 2001), ELVAC (Klote and Alvord 1992) and buildingEXODUS (Galea 
et al. 2004) to simulate a variety of hypothetical evacuation scenarios related to the evacuation in the WTC. The scope of the study was to provide additional context with which to understand the WTC evacuation process and compare the capabilities of different models. The authors successfully employed EXIT89 and buildingEXODUS to model scenarios of the entire WTC towers since both can simulate an evacuation including more than 25000 people and 110 floors. Simulex has a limited maximum number of floors and exits, so it was employed only to simulate phased evacuation scenarios. The ELVAC model was also successfully employed to calculate how many occupants could have reached the ground floor of WTC2 in 16 minutes using shuttle elevators.

Few additional studies using evacuation models to approximate the egress process in high-rise buildings are available in the literature. Pelechano and Malkawi (2008) reviewed the suitability of fine network models in representing the evacuation of a high-rise building. The models selected as case study were STEPS and buildingEXODUS. The main findings focused on the lack of predictive capabilities in terms of human behaviour, with particular emphasis on the need for simulating the communication between agents.

Wong et al. (2005) performed a study in which they used STEPS to demonstrate the increased evacuation efficiency of a 100-storey high-rise building when applying a combined strategy of stairs and elevators. In particular, the strategy employed included the use of sky-lobbies and shuttle elevators. The total number of occupants in the evacuation was approximately 21,000. The geometry of the building was very complex, including three stairs, four refuge floors and 14 shuttle elevators linking the refuge floors and the ground level. The proportion of evacuees waiting for the evacuation elevator on the refuge floors was calibrated through the use of patience coefficients and the estimation of queuing time. The study showed that the total evacuation time can be significantly reduced without complicated procedures, but using an efficient and simple relocation strategy. Wong et al. (2005) pointed out that there is still a need to investigate buildings of different heights, elevator capacity and go into more depth into the possible behavioural factors. An evacuation model was therefore employed in this case to optimize the egress strategy of a high-rise building, showing the impact of an adequate plan on the total evacuation time.

Shen-Wen and Wei-Jou (2011) used buildingEXODUS to investigate the use of evacuation elevators in Taipei 101, the second tallest building in the world. In their study, they adopted buildingEXODUS for the calculation of evacuation using stairs and hand calculations for the calculation of evacuation times using elevators. The simulation results showed that the use of elevators as a method of evacuation can help to reduce the evacuation time in a non-fire emergency. Nevertheless, in the case of fire events, elevator evacuation is less effective due to the particular layout of the building. In this case, the use of an evacuation model was useful to determine the appropriate egress components to employ in relation to the specific characteristics of the building under consideration.

This section presented a set of uses of evacuation models to predict, aid and interpret the safety design of high-rise buildings. It demonstrated that different models can be successfully employed in relation to the type of building and the variables under consideration. Nevertheless, a single definitive model for the simulation of the behavioural issues associated with high-rise building has not been identified. Models generally present different characteristics and they may be suitable to perform different types of studies. Therefore, the authors recommend that - in relation to the complexity of the scenarios under consideration - different models may be used (independently or together) in order to use their predictive capabilities at their best. This strategy has been previously successfully employed in other contexts (e.g. road tunnels (Ronchi 2012; Ronchi 2013)).

\section{Findings on model capabilities for high-rise buildings}

The models described in this chapter present different levels of sophistication in the representation of the evacuation through different egress components. In addition, model users should also be aware of the intrinsic limitations of the models associated with the method employed to represent people movement (i.e. coarse network, fine network or continuous). Evacuation models include few experimental data to implicitly model the behaviours associated with the combined use of different egress components (Nilsson and Jönsson 2011). For this reason evacuation models should provide enough flexibility to allow the user an explicit representation of people behaviours in order to test different relocation strategies. STEPS, Pathfinder and buildingEXODUS all embed implicit or explicit variables to simulate the behavioural factors associated with the evacuation of a high-rise building evacuation (although the buildingEXODUS elevator sub-model is still not officially released). STEPS and Pathfinder can therefore be used to simulate high-rise building evacuation with different egress components. Once the elevator sub-model will be officially released, buildingEXODUS will contain sub-models that will potentially make it suitable for the study of high-rise buildings including a combined use of different components. EXIT89 does not present an elevator sub-model and it is therefore not suitable when evaluating the use of this egress component. The current version of FDS+Evac (2.3.1) can be used to simulate complex behavioural aspects concerning the evacuation of high-rise buildings; 
nevertheless its use is not recommended for these scenarios because of the high times required by the model (both for setting up the scenarios as well as the computational times to run the simulations). In addition, the elevator sub-model is still not officially released. The review of the characteristics of ELVAC, ELEVATE, and the Building Traffic Simulator (BTS) shows that they may be employed to simulate vertical evacuation scenarios in high-rise buildings. In contrast, they present limitations in the representation of the behavioural aspects associated with the use of different egress components (they are mostly represented implicitly). They are therefore not considered suitable to analyse scenarios where there is a need to directly study the interaction between vertical and horizontal egress components (e.g., evacuation elevators and a sky-bridge).

A set of key points have been identified in this section about modelling studies for the analysis of evacuation in high-rise buildings:

- Evacuation models can be efficiently used to study high-rise building evacuations

- Evacuation models present different characteristics and features

- The interactions between the occupants and the infrastructure can be represented either implicitly or explicitly, but human behaviour data for the calibration of model input are scarce

- The characteristics of a set of evacuation models have been reviewed with a particular emphasis on their ability to simulate multiple egress components

- There is not a definitive model to be used for the study of high-rise building evacuations, but some models present enough flexibility to represent human behaviour in this type of buildings

- Few applications of evacuation models about high-rise building evacuations are available in the literature

\section{Discussion}

This study contains information from a significant amount of literature related to human behaviour and modelling studies for high-rise building evacuations. The work includes the analysis of the main factors associated with different building uses, egress components and egress strategies. A review of the capabilities of a set of relevant egress models to perform the simulation of high-rise buildings has been performed and a series of previous examples of their application have been presented. The most important observations and results of these studies have been summarised. This section presents a brief discussion to sum up these observations and analyse the results of the review performed.
The review showed that the first question designers should address when approaching the conceptual fire safety design of a high-rise building is the purpose of the building. Three main building uses were considered in this study, namely office buildings, residential buildings (e.g. hotels, apartments, etc.) and health care facilities. The review showed that the compartmentation and the design (either it is traditional or an open space concept) can strongly affect the choice of the adequate egress strategy. The defend-in-place strategy was generally found adequate (Proulx 2001) for residential buildings which present specific characteristics, such as the presence of tools to perform defend-in-place activities (e.g. sheets, towels, etc.), compartmentation, etc. Delayed evacuation strategy is appropriate for buildings designed for people that are not able to perform self-rescue activities without external aid, e.g., health care facilities. From a behavioural perspective, the building use affects several factors of the evacuation process such as the familiarity with the building, the degree of alertness, and level of training of the evacuees. Fire safety systems (e.g. voice communication systems, alarms, smoke management systems, etc.), and the availability of staff are other key factors of the evacuation process.

The main characteristics of the egress components available in high-rise buildings have been discussed with particular attention on the means of evacuation that have been (or might be) introduced in the fire safety designs, e.g. emergency elevators, sky-bridges, refuge floors, etc. The review highlighted that research has so far focused more on the design aspects of the egress components, while few research studies have been carried out on the behavioural processes that take place during a high-rise building evacuation (Kinsey et al. 2010). In particular, there is a need to further investigate the behaviours of the occupants in the case of the choice between multiple egress components. There is also a need to analyse the impact that specific variables may have on the evacuation process, such as the use of different messaging strategies, the level of training and the availability of staff (Kuligowski and Hoskins 2012).

The capabilities of a set of evacuation models among the most used by practitioners have been reviewed in order to analyse their suitability to simulate high-rise building evacuations. Models included in this review were STEPS (Mott MacDonald 2011), Pathfinder (Thunderhead Engineering 2011), buildingEXODUS (Galea et al. 2004), FDS+Evac (Korhonen and Hostikka 2010), EXIT89 (Fahy 1996), ELVAC (Klote and Alvord 1992), ELEVATE (Peters 2002), Building Traffic Simulator (BTS) (Siikonen 1993), and BUMMPEE (Christensen and Sasaki 2008).

Models specifically designed to test circulation lift strategies are not fully suitable for simulating evacuation scenarios which involve both horizontal and vertical egress 
components since horizontal components are generally represented implicitly. Models that do not include submodels for emergency elevators are not considered as adequate to simulate high-rise building evacuations because this component is becoming an integral part of the fire safety design for this type of buildings. A set of evacuation models embedding sub-models to simulate emergency elevators has been reviewed with particular attention on the interaction between this egress component and other egress components (e.g. stairs, refuge floors, sky-bridges). The reliability of the results produced by some of these models is strongly user-dependent since modellers need to perform a significant calibration effort in order to simulate the possible behaviours of the occupants that may take place in the case of multiple egress components. Another important aspect to be taken into consideration is the time required to set up and run the scenarios. The complexity of high-rise building evacuations require models able to simulate significant number of occupants and for this reason computational time plays a key role in the suitability of the models. Therefore, the authors recommend that models which present slow computational times and setup times are not used. The review showed that models have different characteristics and they may be suitable to study different aspects of the evacuation process. For this reason, the authors argue that their predictive capabilities may be enhanced if different models are employed to study specific aspects of the evacuation process. The application of a multi-model approach allows the modeller to use the strengths of each model and apply the most suitable algorithms to simulate each specific behavioural variable.

The review shows different case studies in which evacuation models have been useful tools for simulating egress strategies and test the effectiveness of different fire safety designs (see Modelling case studies section). Nevertheless, few case studies are available in the literature for the case of high-rise building evacuations and few comparisons of different strategies have been performed. In addition, few validation studies have been performed, mainly because of the lack of real world data available. There are only a small number of high-rise evacuations where data has been collected. Typically the unique nature of such events brings in to question their general applicability. The application of evacuation models to simulate the WTC evacuation process shows the benefits of the use of evacuation models from both a design and a procedural perspective.

\section{Future research}

Specific factors of the evacuation process in high-rise buildings need further studies. One of the future recommended requirements for the evacuation research community is the study of the impact of fatigue on the evacuation process. Given the increasing height of buildings and the gradual reduction in the physical ability of the population, this appears as a key variable that has been so far mainly ignored in evacuation models. An important factor that also needs investigation is the effect of group dynamics in the evacuation process. In this context, the studies of the WTC evacuation showed the relevance of the impact of the formation of groups during the evacuation through stairs. An important variable that needs to be enhanced in evacuation models is the possibility to explicitly implement the impact of the actions of staff on the evacuation process. In particular, there is a need to develop algorithms able to represent the effects of communications between agents. A final factor that needs further studies is the impact of the presence of people with disabilities. Evacuation models permit the study and review of different egress strategies that can be specifically designed for this type of occupant. Nevertheless, the current capabilities of evacuation models are not enhanced to take into consideration the variability of the impairments that can affect the evacuation process and the subsequent group dynamics that may take place. Further studies on this topic are therefore required.

\section{Conclusion}

This paper presents the findings of a literature review conducted on human behaviour and modelling research for high-rise building evacuations. Three categories of high-rise buildings have been taken into account, namely office buildings, residential buildings and health care facilities. The individual or combined use of egress components has been analysed as well. The review shows that the effectiveness of the egress components is associated with the building use and the population involved. Evacuation models are useful tools for the study of relocation strategies but their predictive capabilities are linked to their flexibility in representing egress components and complex behavioural processes. Future research and model developments should focus on the study of the impact of staff actions, group dynamics, people with disabilities and the effects of fatigue.

\section{Competing interests}

The authors declare that they have no competing interests.

\section{Authors' contributions}

ER and DN carried out the problem identification and developed the method for the selection and evaluation of relevant material for the literature review. ER drafted the manuscript. DN suggested modifications in the manuscript critically revising its content. Both authors read and approved the final manuscript.

\section{Acknowledgements}

This work is a part of a project funded by the Fire Protection Research Foundation of the National Fire Protection Association (NFPA), namely "Assessment of Total Evacuation Systems for Tall Buildings". The focus of the project is to study the suitability of egress models to achieve improvements to life safety of tall buildings involving the use of different egress

components. The authors wish to thank Amanda Kimball and Kathleen 
Almand from the Fire Protection Research Foundation to provide technical support during this study. The authors also thank the Technical Panel of the project for their guidance during this study. The Technical Panel includes Kristin Bigda, Kim Clawson, Rita Fahy, Morgan Hurley, Jay Popp, James Shea, Jeff Tubbs, Pete Weismantle, Nate Wittasek and Steve Wolin.

Received: 23 November 2012 Accepted: 5 November 2013 Published: 20 November 2013

\section{References}

Adams APM, Galea ER (2011) An Experimental Evaluation of Movement Devices used to assist People with Reduced Mobility in High-Rise Building Evacuations. In: Peacock RD, Kuligowski ED, Averill JD (ed) Proceedings of the 5th Pedestrian and Evacuation Dynamics Conference. National Institute of Standards and Technology. Springer, Maryland USA, pp 129-138

American Disability Act (2010) Standards for Accessible Design. Department of Justice, USA

Amor HB, Murray J, Obst O, et al. (2006) Fast, Neat, and Under Control: Arbitrating Between Steering Behaviors. In: Rabin S (ed) Proceedings of the Al Game Programming Wisdom 3. Charles River Media, pp 221-232

Andrée K, Bengtson S (2012) Analysis of the impact of training, communication and egress strategy in an apartment fire. In: Proceedings of the Human Behaviour in Fire Symposium 2012. Interscience Communication, Cambridge, UK

Ariff A (2003) Review of Evacuation Procedures for Petronas Twin Towers. In: Proceedings of the CIB-CTBUH International Conference on Tall Buildings. CIB Publication no: 290, Kuala Lumpur

ASME/A17 (2013) Safety Code for Elevators and Escalators. Task Groups on Use of Elevators by Firefighters and Use of Elevators for Occupant Egress. American Society of Mechanical Engineers, New York, USA

Averill JD, Mileti DS, Peacock RD, Kuligowski ED, Groner N, Proulx G, Reneke AP, Nelson HE (2005) Final Report on the Collapse of the World Trade Center Towers. Federal Building and Fire Safety Investigation of the World Trade Center Disaster, Occupant Behaviour. Egress and Emergency Communications. September. NIST NCSTAR 1-7. National Institute of Standards and Technology, Gaithersburg, USA

Barney GC (2003) Vertical Transportation in Tall Buildings. Elevator World, pp 66-75

Bazjanac V (1977) Simulation of elevator performance in high-rise buildings under conditions of emergency. In: Conway DJ (ed) Human Response to Tall Buildings. Dowden, Hutchnison, and Ross, Stroudsburg, PA, pp 316-328

BBR (2012) Regelsamling för byggande. Boverket, Karlskrona, Sweden

Best R, Demers D (1982) Investigation report on the MGM Grand Hotel fire, Las Vegas, Nevada, November 21, 1980. National Fire Protection Association, Boston, USA

Biava M, Khier W, Vigevano L (2012) CFD prediction of air flow past a full helicopter configuration. Aerosp Sci Technol 19(1):3-18

Blair AJ, Milke JA (2011) The Effect of Stair Width on Occupant Speed and Flow Rate for Egress of High Rise Buildings. In: Peacock RD, Kuligowski ED, Averill JD (ed) Pedestrian and Evacuation Dynamics. Springer US, Boston, USA, pp 747-750

Blake SJ, Galea ER, Westeng H, Dixon AJP (2004) An Analysis of Human Behaviour during the WTC Disaster of 11 September 2001 based on Published Survivor Accounts. In: Proceedings of the 3rd International Symposium on Human Behaviour in Fire, 1-3 September 2004. Interscience Communication Ltd, Belfast, UK, pp 181-192

Boston properties (2012) Emergency procedures and evacuation plans of the Prudential Tower. Boston properties, Boston, USA

Boyce KE, Shields TJ (1999a) Towards the characterisation of building occupancies for fire safety engineering: prevalence, type and mobility of disabled people. Fire Technol 35(1):35-50

Boyce KE, Shields TJ (1999b) Towards the characterisation of building occupancies for fire safety engineering: capabilities of disabled people moving horizontally and up an incline. Fire Technol 35(1):51-67

Boyce KE, Shields TJ, Silcock GWH (1999) Toward the characterization of building occupancies for fire safety engineering: capability of people with disabilities to read and locate exit signs. Fire Technol 35(1):79-86

Boyce KE, Purser D, Shields TJ (2009) Experimental Studies to Investigate Merging Behaviour in a Staircase. In: Proceedings of the 4th International Symposium on Human Behaviour in Fire. Interscience Communications Itd, Cambridge, pp 111-122
BSI, British Standards Institution BS 9999:2008 (2008) Code of Practice for Fire Safety in the Design, Management and Use of Buildings. BSI Group, London UK

BSI, British Standards Institution PD 7974-6 (2004) The application of fire safety engineering principles to fire safety design of buildings. Human factors. Life safety strategies. Occupant evacuation, behaviour and condition (Sub-system 6) BSI Group, London UK

Bukowski RW (2005) Protected Elevators for Egress And Access During Fires. In: Tall Buildings, Workshop on Building Occupant Movement During Fire Emergencies. National Institute of Standards and Technology, Special Publications, pp 14-21

Bukowski RW (2009) Emergency Egress from Buildings, Part 1: History and Current Regulations for Egress Systems Design. NIST Technical Note: 1623. National Institute of Standards and Technology, Gaithersburg, USA

Bukowski RW (2010a) International Applications of Elevators for Fire Service Access and Occupant Egress in Fires. Council on Tall Buildings and Urban Habitat (CTBUH) Journal 2010, Issue III, Chicago, USA, pp 28-33

Bukowski RW (2010b) Applications of Elevators for Occupant Egress in Fires. In: Proceedings of the SFPE Technology Conference 2010. Society of Fire Protection Engineers, New Orleans, LA, USA

Bukowski RW, Klote JW, Kuligowski ED (2009) Summary of NIST/GSA Cooperative Research on the Use of Elevators During Fire Emergencies. In: Peacock RD (ed). NIST Special Publication 1620, Gaithersburg, USA

Bureau of Indian Standards (2005) Fire and Life Safety. National Building Code of India, India

Cepolina E (2009) Phased evacuation: an optimisation model which takes into account the capacity drop phenomenon in pedestrian flows. Fire Saf J 44:532-544

Chien S, Wen W (2011) A research of the elevator evacuation performance and strategies for Taipei 101 Financial Center. J Disaster Res 6:6

Choi J, Hwang H, Hong W (2011) Predicting the probability of evacuation congestion occurrence relating to elapsed time and vertical section in a high-rise building. In: Peacock (ed) Pedestrian and Evacuation Dynamics Conference 2010. Gaithersburg, Maryland. doi:10.1007/978-1-4419-9725-8_

Christensen K, Sasaki Y (2008) Agent-based emergency evacuation simulation for individuals with disabilities in the population. J Artificial Societies Social Simulation 11:39

Christensen KM, Collins SD, Holt JM, Phillips CN (2006) The relationship between the design of the built environment and the ability to egress of individuals with disabilities. Rev Disability Stud 2:24-34

Clark County Fire Department (1981) MGM Report. Clark County Fire Department, Las Vegas, USA

Clawson K, O'Connor DJ (2011) Considerations and Challenges for refuge Areas in Tall Buildings. In: Proceedings of the CTBUH 2011 World Conference, 332-338 Seoul. Council of Tall Buildings and Urban Habitat

Evacmod (2012). www.evacmod.net

Fahy RF (1996) Enhancement of EXIT89 and analysis of World Trade Center data, NIST-GCR-95-684. Fire Analysis and Research Division. National Institute of Standards and Technology, Gaithersburg, USA

Frantzich H (1996) Fire Safety Risk Analysis of a Health Care Facility. Department of Fire Safety Engineering and Systems Safety. Lund University, Lund, Sweden

Friedman R (1992) An international survey of computer models for fire and smoke. J Fire Prot Eng 4:81-92

Galbreath M (1969) Fire Research Note 8. National Research Council of Canada, Ottawa, Canada

Galea ER, Blake S (2004) Collection and Analysis of Human Behaviour Data Appearing in the Mass Media Relating to the Evacuation of the World Trade Centre Towers of 11 September 2001, Report prepared for the Building Disaster Assessment Group (BDAG). Office of the Deputy Prime Minister, London

Galea ER, Gwynne SMV, Lawrence PJ, Filippidis L, Blackshields D, Cooney D (2004) buildingEXODUS User Guide and Technical Manual. University of Greenwich, London, UK

Galea ER, Hulse L, Day R, Siddiqui A, Sharp G, Shields J, Boyce KE, Summerfield L, Canter D, Marselle M, Greenall P (2008a) The UK WTC9/11 evacuation study: an overview of the methodologies employed and some preliminary analysis. In: Proceedings of the 4th Pedestrian and Evacuation Dynamics Conference. University of Wuppertal, Germany

Galea ER, Sharp G, Lawrence PJ, Holden R (2008b) Approximating the evacuation of the World Trade Center North Tower using computer simulation. J Fire Prot Eng 18(2):85-115 
Galea ER, Sharp G, Lawrence P (2008c) Investigating the representation of merging behavior at the floor-stair interface in computer simulations of multi-floor building evacuations. J Fire Prot Eng 18(4):291-316

GB50045-95 (2005) Code for Fire Protection Design of Tall Buildings [Translated from Chinese]. National Standard of People's Republic of China. State Bureau of Quality and Technical Supervision, Ministry of Construction of the People's Republic of China, Beijing, China

General Services Administration (1971) Public Building Service International Conference on Fire safety in High-Rise Buildings, April 12-16, Airlie House, Warrenton, Va. General Services Administration, Washington, DC

Graat E, Midden C, Bockholts P (1999) Complex evacuation; effects of motivation level and slope of stairs on emergency egress time in a sports stadium. Saf Sci 31:127-144

Groner N (2002) A compelling case for emergency elevator systems. Fire Eng 155(10):126-128

Gwynne SMV, Rosenbaum E (2008) Employing the Hydraulic Model in Assessing Emergency Movement. In: SFPE Handbook of Fire Protection Engineering, 4th edition. National Fire Protection Association, Quincy, USA. 3-396-3-373

Gwynne SMV, Galea ER, Owen M, Lawrence PJ, Filippidis L (1999) A review of the methodologies used in the computer simulation of evacuation from the built environment. Build Environ 34(6):741-749

Gwynne SMV, Purser DA, Boswell DL (2010) Pre-warning staff delay: a forgotten component in ASET/RSET calculations. In: Peacock RD, Kuligowski ED, Averill $J D(e d)$ Proceedings of the 5th Pedestrian and Evacuation Dynamics Conference, National Institute of Standards and Technology. Springer, Maryland USA, pp 243-253

Hall JR (2011) High-Rise building fires. National Fire Protection Association, Quincy, USA

Harding P, Amos M, Gwynne SMV (2010) Prediction and Mitigation of Crush Conditions in Emergency Evacuations. In: Klingsch WWF, Rogsch C, Schadschneider A, Schreckenberg M (ed) Pedestrian and Evacuation Dynamics 2008. Springer Berlin Heidelberg, Berlin, Heidelberg, pp 233-246

Hassanain MA (2009) On the challenges of evacuation and rescue operations in high-rise buildings. Struct Surv 27(2):109-118

Hedman G (2009) Stair Descent Devices: An Overview Of Current Devices And Proposed Framework For Standards And Testing. PE, CPE University of Illinois at Chicago, Usa. In: Proceedings of the 4th International Symposium on Human Behaviour in Fire. Interscience Communications Ltd, Cambridge, pp 601-606

Heyes E (2009) Human Behaviour Considerations in the Use of Lifts for Evacuation from High Rise Commercial Buildings. Phd dissertation. University of Canterbury, Christchurch, New Zealand

Hong Kong Building Department (1996) Code of Practice for Provisions of Means of Escape in Case of Fire and Allied Requirement. Building Authority, Hong Kong

Hunt A, Galea E, Lawrence P (2012) An Analysis of the performance of trained staff using movement assist devices to evacuate the non-ambulant. In: Proceedings of the 5th International Symposium on Human Behaviour in Fire. Interscience Communications Ltd, Cambridge UK, pp 328-339. 19-21 September 2012

IES (2001) Simulex user manual; evacuation modeling software. Integrated Environmental Solutions Inc, Glasgow, UK

International Building Code (2009) International Code Council, Country Club Hills, IL 60478 and Building Construction and Safety Code, NFPA 50002009 edition. National Fire Protection Association, Quincy, USA

Johnson CW (2005) Lessons from the evacuation of the world trade centre, 9/11 2001 for the development of computer-based simulations. Cognition Technol Work 7(4):214-240

Jönsson A, Andersson J, Nilsson D (2012) A Risk Perception Analysis of Elevator Evacuation in High-Rise Buildings. In: Proceedings of the 5th Human Behaviour in Fire Symposium. Interscience Communication Ltd, Cambridge, UK

Khanna A (2003) Inflatable Ejection Module (IEM): An emergency egress system for tall buildings. In: Proceedings of the CIB-CTBUH International Conference on Tall Buildings, Strategies for Performance in the Aftermath of the World Trade Centre, vol 290. ClB Publication, Kuala Lumpur, pp 739-744

Kinsey MJ (2011) Vertical Transport Evacuation Modelling. University of Greenwich, Dissertation, London, UK

Kinsey MJ, Galea ER, Lawrence PJ (2009) Investigating the use of elevators for high-rise building evacuation through computer simulation. In: 4th International Symposium on Human Behaviour in Fire 2009: Conference Proceedings. Interscience Communications Ltd, London, UK, pp 85-96
Kinsey MJ, Galea ER, Lawrence PJ (2010) Human factors associated with the selection of lifts/elevators or stairs in emergency and normal usage conditions. Fire Technol 8(1):3-26. doi:10.1007/s10694-010-0176-7

Kinsey MJ, Galea ER, Lawrence PJ (2012) Modelling Human Factors And Evacuation Lift Dispatch Strategies. In: Proceedings of the 5th International Symposium on Human Behaviour in Fire 2012. Interscience Communication Ltd, Cambridge (UK), pp 386-397

Klote JH (1983) Elevators as a means of fire escape, American Society of Heating Refrigerating and Air Conditioning Engineers Transactions. 89(2):1-16. NBSIR $82-2507$

Klote JH, Alvord DM (1992) Routine for Analysis of the People Movement Time for Elevator Evacuation, vol NISTIR 4730. National Institute of Standards, Gaithersburg, USA

Klote JH, Deal SP, Levin BM, Groner NE, Donoghue EA (1992a) Workshop on Elevator use during fires, vol 3. NISTIR 4993. National Institute of Standards and Technology, Gaithersburg, USA

Klote J, Alvord A, Levin B, Groner N (1992b) Feasibility and Design Considerations of Emergency Evacuation by Elevators. National Institute of Standards and Technology, Gaithersburg, USA, NISTIR. 4870

Klote JH, Deal SP, Donoghue B, Levin BM, Groner NE (1993) Fire Evacuation by Elevators. National Institute of Standards and Technology. In: Bukowski RW, Burgess SR, Reneke PA (ed) Elevator World. Special Publication 983; Collected Publications Related to the Use of Elevators During Fires. Vol. 41, No. 6, 66-70,72-75

Koo J, Kim YS, Kim B-I (2012) Estimating the impact of residents with disabilities on the evacuation in a high-rise building: a simulation study. Simul Model Pract Th 24:71-83

Korhonen T, Hostikka S (2010) Fire Dynamics Simulator with Evacuation: FDS +Evac Technical Reference and User's Guide. FDS 5.5.3, Evac 2.3.1. VTT Technical Research Centre of Finland, Espoo, Finland. Working papers 119

Kratchman JA (2007) An Investigation on the Effects of Firefighter Counterflow. and Human Behavior in A Six-Story Building Evacuation. Department of Fire Protection Engineering. University of Maryland

Kuligowski ED (2011) Terror defeated: Occupant sensemaking, decision-making and protective action in the 2001 World Trade Center Disaster. University of Colorado, Dissertation

Kuligowski ED, Bukowski RW (2004) Design of occupant egress systems for tall buildings, use of elevators in fires and other emergencies workshop. In: Proceedings, 2-4 March 2004. Co-sponsored by American Society of Mechanical Engineers (ASME International); National Institute of Standards and Technology (NIST); International Code Council (ICC); National Fire Protection Association (NFPA); U.S. Access Board and International Assn of Fire Fighters (IAFF). Atlanta, GA, pp 1-12

Kuligowski ED, Hoskins BL (2012) Recommendations for Elevator Messaging Strategies. NIST report 1730. National Institute of Standards and Technology, Gaithersburg, USA

Kuligowski ED, Peacock RD, Hoskins BL (2010) A Review of Building Evacuation Models NIST, Fire Research Division. Technical Note 1680, 2nd edition. National Institute of Standards and Technology, Washington, US

Kuligowski ED, Peacock RD, Averill JD (2011) Modeling the evacuation of the World Trade Center Towers on September 11, 2001. Fire Technol. doi:10.1007/s10694-011-0240-y

Lay S (2007) Alternative evacuation design solutions for High-rise buildings. Struct Design Tall Spec Build 16:487-500

Levin B, Groner N (1994) Human Factors Considerations for the potential use of elevators for fire evacuation of FAA Air Traffic Control Towers', NIST Technical Note, NIST-GCR-94-656. National Institute of Standards and Technology, Gaithersburg, USA

Mallonee S, Shariat S, Stennies G, Waxweiler R, Hogan D, Jordan F (1996) Physical injuries and fatalities resulting from the Oklahoma City bombing. J Am Med Assoc 276(5):382-387

McGrattan K, Hostikka S, Floyd J, Baum H, Rehm R, Mell W, McDermott R (2008) Fire dynamics simulator (version 5), technical reference guide. National Institute of Standards and Technology Special Publication, Gaithersburg, MD. 1018-5

Melinek SJ, Booth S (1975) Current Paper CP 96/75. Building Research Establishment, Borehamwood, UK

Ming Lo S, Will BF (1997) A view to the requirement of designated refuge floors in high-rise buildings in Hong Kong. Fire Safety Sci 5:737-745

Mott MacDonald Simulation Group (2011) Simulation of Transient Evacuation and Pedestrian movementS STEPS User Manual 4.1 Version. Mott MacDonald Group Limited, Croydon, UK 
NFPA (2012) NFPA 101 Life Safety Code. National Fire Protection Association, Quincy (USA)

Nilsson D (2007) Computer modeling of evacuation and fire. An inventory of three approaches [in Swedish]. Report 3142. Lund University, Lund, Sweden

Nilsson D, Jönsson A (2011) Design of evacuation systems for elevator evacuation in high-rise buildings. J Disaster Res 6(6):600-609

Noordermeer RHJ (2010) Usage of Lifts for the Evacuation of High-Rise Projects. Delft University, Dissertation

Olenick SM, Carpenter DJ (2003) An updated international survey of computer models for fire and smoke. J Fire Prot Eng 13(2):87-110

Pauls JL (1978) Calculating evacuation times for tall buildings. Fire Safety J 12:213-236

Pauls JL (1988) Egress Time Criteria Related to Design Rules in Codes and Standards. In: Sime JD (ed) Safety in the Built Environment. E and F.N. Spon, New York

Pauls JL (1994) Vertical Evacuation in Large Buildings: Missed Opportunities for Research.. Disaster Management

Pauls JL (2005) Evacuation of Large High-Rise Buildings: Reassessing Procedures and Exit Stairway Requirements in Codes and Standards. In: Proceedings of the 7th Conference of the Council of Tall Buildings and Urban Habitat. New York, USA, pp 16-19

Pauls JL, Jones BK (1980) Building Evacuation: Research Methods and Case Studies. In: Canter D (ed) Fires and Human Behaviour. Wiley, Chichester

Pauls JL, Fruin J, Zupan J, Waldau, Gattermann, Knoflacher, Schreckenberg A (2007) Minimum Stair Width for Evacuation, Overtaking Movement and Counterflow: Technical bases and suggestions for the past, present and future. In: Proceedings of the 3rd Pedestrian and Evacuation Dynamics Conference. Springer-Verlag, Berlin, pp 57-69

Peacock RD (2009) Summary of NIST/GSA Cooperative Research on the use of elevators During Fire Emergencies. Building and Fire Research Laboratory. National Institute of Standards and Technology. Special Publication 1620, Gaithersburg, USA

Peacock RD, Averill JD, Kuligowski ED (2009) Stairwell Evacuation From Buildings: What We Know We Don't Know. NIST Report 1624. National Institute of Standards and Technology. Special Publication 1620, Gaithersburg, USA

Peacock RD, Kuligowski ED, Averill JD (2012a) Building Occupant Safety Research. NIST SP - 1131. National Institute of Standards and Technology, Gaithersburg, USA

Peacock RD, Hoskins BL, Kuligowski ED (2012b) Overall and local movement speeds during fire drill evacuations in buildings up to 31 stories. Special Issue on Evacuation and Pedestrian Dynamics. Safety Sci 50(8):1655-1664

Pelechano N, Malkawi A (2008) Evacuation simulation models: challenges in modeling high rise building evacuation with cellular automata approaches. Automat Constr 17:377-385

Peters RD (2002) Current Technology and Future Developments in Elevator Simulation. Technical Note, Int J Elevator Eng 4(2)

Proulx G (1995) Evacuation time and movement in apartment buildings. Fire Safety J 24(3):229-246

Proulx G (2001) High-rise evacuation: a questionable concept. In: Proceedings of the 2nd International Symposium on Human Behaviour in Fire. Interscience Communication Ltd, Boston, MA, USA, pp 221-230

Proulx G (2009) The use of elevators for egress. Discussion panel. In: Proceedings of the 4th International Symposium on Human Behaviour in Fire. Robinson College, Cambridge, Interscience Communication Ltd, UK

Proulx G, Reid MA (2006) Occupant behaviour and evacuation during the Chicago Cook County Administration Building Fire. J Fire Prot Eng 16:283-309. SAGE Publications, SFPE

Reynolds CW (1999) Steering Behaviors For Autonomous Characters. Proceedings of the Game Developers Conference. Miller Freeman Game Group, San Francisco, California, In, pp 763-782

Romano J (2003) Façade Emergency Exits Concept. In: Proceedings of the CIB-CTBUH International Conference on Tall Buildings. CIB Publication no: 290, Kuala Lumpur, pp 747-749

Ronchi E (2012) Evacuation modelling in road tunnel fires (Doctoral Dissertation). Politecnico di Bari, Bari, Italy

Ronchi E (2013) Testing the predictive capabilities of evacuation models for tunnel fire safety analysis. Saf Sci 59:141-153

Ronchi E, Kinsey M (2011) Evacuation models of the future. Insights from an online survey on user's experiences and needs. In: Capote J (ed) Advanced Research Workshop Evacuation and Human Behaviour in
Emergency Situations EVAC11. University of Cantabria, Santander, Spain, pp 145-155

Ronchi E, Nilsson D (2013) Assessment of total evacuation strategies in Tall Buildings. Fire Protection Research Foundation. Technical Report, National Fire Protection Association, Quincy, USA

Ronchi E, Berloco N, Colonna P, Alvear D, Capote J, Cuesta A (2011) Developing a Database for simulating disabled people within evacuation models [in Italian]. National Conference on Safety of Complex System 2011, Bari, Italy

Santos G, Benigno Aguirre E (2004) A Critical Review of Emergency Evacuation Simulation Models. In: Proceedings of the NIST Workshop on Building Occupant Movement during Fire Emergencies. Disaster Research Center, University of Delaware

Sciencedirect (2012). www.sciencedirect.com/

Sekizawa A, Ebihara ME, Notake H, Kubota K, Nakano M, Ohmiya Y, Kaneko H (1999) Occupants' behaviour in response to the high-rise apartments fire in Hiroshima City. Fire and materials. Special issue. Human Behav Fire 23(6):297-303

Shen-Wen C, Wei-Jou W (2011) A research of the elevator evacuation performance and strategies for Taipei 101 Financial Cente. J of Disast Res 6:6

Shi L, Xie Q, Cheng X, Chen L, Zhou Y, Zhang R (2009) Developing a database for emergency evacuation model. Build Environ 44(8):1724-1729

Shields TJ, Boyce KE, McConnell N (2009) The behaviour and evacuation experiences of WTC 9/11 evacuees with self-designated mobility impairments. Fire Saf J 44(6):881-893

Siikonen M (1993) Elevator traffic simulation. Simulation 61(4):257-267

Sime JD (1987) Access and Egress for the Handicapped in Public Buildings. In: Haber G, Blanks T (ed) Building Design for Handicapped and Aged Persons: An International Inventory. Portsmouth, UK, p 27

Singapore Civil defence Force (2006) Additional Fire Safety Requirements for super high-rise residential buildings. Fire Safety and Shelter Bureau. Retrieved on the 22/05/2012 from www.scdf.gov.sg

Spearpoint M, MacLennan HA (2012) The effect of an ageing and less fit population on the ability of people to egress buildings. Saf Sci 50:1675-1684

Summon (2012). www.serialssolutions.com/en/services/summon/

Swedish Accident Investigation Board (2010) Report RO 2010:01 Lägenhetsbrand, Kuddbygränd 12, Rinkeby, Stockholms län, den. 25 juli 2009. Swedish Accident Investigation Board, Stockholm, Sweden

Tavares RM (2008) Evacuation processes versus evacuation models: "Quo Vadimus"? Fire Technol 45:419-430

The Building Regulation (2006) Fire Safety, Approved Document B. Office of the Deputy of the Prime Minister, London UK

Thunderhead Engineering (2011) Pathfinder 2011.1.1702 Version. Technical Reference, Manhattan KS, USA

Torero JL, Quintiere JG, Steinhaus T (2002) Fire Safety in High-rise buildings: Lessons Learned from the WTC. Jahresfachtagung der Vereingung zur Forderrung des Deutschen Brandschutzez e. V, Dresden, Germany

Tubbs J, Meacham B (2009) Selecting appropriate evacuation strategies for super tall buildings: Current challenges and needs. In: Proceedings of the 4 th International Symposium on Human Behaviour in Fire. Robinson College, Cambridge, pp 41-50. 13-15 July 2009. Interscience Communications

United States Fire Administration (1993) The World Trade Center Bombing: Report and Analysis. Technical Report. Department of Homeland and Security, New York City, New York

Watts JM (1987) Computer models for evacuation analysis. Fire Saf J 12:237-245

Weismantle P, Smith G, Sheriff M (2007) Burj Dubai: an architectural technical design case study. Struct Design Tall Spec Build 16:335-360

Williamson BJ, Demirbilek N (2010) Use of lifts and refuge floors for fire evacuation in high rise apartment buildings. In: Proceedings of the 44th Annual Conference of the Architectural Science Association, ANZASCA 2010 Unitec Institute of Technology, Auckland, New Zealand

Wong HLK, Luo MC (2005) Total Building Evacuation Strategy for High Rise Buildings, Tall Buildings. In: Cheung YK, Chau KW (ed) Proceeding of 6th International Conference on Tall Buildings, pp 1113-1120

Wong HLK, Hui M, Guo D, Luo M (2005) A Refined Concept on Emergency Evacuation by Lifts. Proceedings of the Eighth International Symposium on Fire Safety Science. Beijing, China, pp 599-610

Wood PG (1972) Fire Research Note 953. Building Research Establishment, Borehamwood, UK

Wood A (2003) Pavements in the Sky: The use of the Skybridge in Tall Buildings. In: Proceedings of the CIB-CTBUH International Conference on Tall Buildings. CIB Publication no:290, Kuala Lumpur 
Wood A (2007) Alternative Forms of Tall Building evacuation. In: Proceedings of: AEI/NIST Conference on High-Rise Building Egress. National Institute of Standards and Technology conference, 'Symposium on High-Rise Building Egress'. McGraw-Hill Auditorium, New York, USA

Wood A, Chow WK, McGrail D (2005) The skybridge as an evacuation option for tall buildings for highrise cities in the Far East. J Appl Fire Sci 13(2):113-124. doi:10.2190/1417-HHOK-1W74-170R

Zmud M (2007) Public Perceptions of High-rise Building Safety and Emergency Evacuation Procedures Research Project'. The Fire Protection Research Foundation. Quincy, USA

doi:10.1186/2193-0414-2-7

Cite this article as: Ronchi and Nilsson: Fire evacuation in high-rise buildings: a review of human behaviour and modelling research. Fire Science Reviews 2013 2:7.

\section{Submit your manuscript to a SpringerOpen ${ }^{\circ}$} journal and benefit from:

- Convenient online submission

- Rigorous peer review

- Immediate publication on acceptance

- Open access: articles freely available online

- High visibility within the field

- Retaining the copyright to your article 